\title{
PERCEPÇÃO E CLASSIFICAÇÃO DE INSETOS POR MORADORES DA COMUNIDADE VILA PINDARÉ, BURITICUPU, MARANHÃO - ESTUDO DE CASO
}

Gisely Souza do Nascimento Lima*, Reinaldo Lucas Cajaiba ${ }^{2}$, Elson Silva de Sousa ${ }^{3}$

${ }^{1}$ Graduanda em Licenciatura em Ciências Biológicas, Instituto Federal do Maranhão, campus, Buriticupu, MA

2Doutor em Ciências Ambientais, pesquisador do Laboratório de Ecologia e Conservação, Instituto Federal do Maranhão, Campus Buriticupu

${ }^{3}$ Doutorando em Educação em Ciências e Matemática pela Rede Amazônica de Educação em Ciências e Matemática, pesquisador do Laboratório de Ecologia e Conservação, Instituto

Federal do Maranhão, Campus Buriticupu

* autor correspondente: giselysouzadonascimento@outlook.com

Recebido em: 15/05/2020 - Aprovado em: 15/06/2020 - Publicado em: 30/06/2020 DOI: 10.18677/EnciBio_2020B37

\begin{abstract}
RESUMO
Os insetos exercem funções indispensáveis nos ambientes em que ocorrem, entretanto, são vistos de forma negativa pelo homem. Dessa forma, conhecer a percepção/interação do homem com os insetos é extremamente importante para unir os conhecimentos científicos e tradicionais. O presente estudo teve como objetivo analisar a percepção e classificação de insetos por moradores da comunidade Vila Pindaré, município de Buriticupu, Maranhão. A pesquisa de campo ocorreu no período de agosto a outubro de 2019, através do uso de questionários semiestruturados, realizado com 55 moradores da comunidade. Os dados obtidos revelaram que o termo "inseto" foi associado a diversos grupos taxonômicos, não pertencentes à classe Insecta, como aranha (Araneae), seguido por rato (Muridae) e escorpião (Scorpiones). Além disso, a maioria dos entrevistados apresentam um sentimento negativo em relação aos insetos como animais nojentos, horríveis, perigosos e transmissores de doenças, porém, reconhecem a sua importância para a natureza.
\end{abstract}

PALAVRAS-CHAVE: Conhecimento popular; Etnobiologia, etnoentomologia.

\section{PERCEPTION AND CLASSIFICATION OF INSECTS BY RESIDENTS OF THE VILA PINDARÉ COMMUNITY, BURITICUPU, MARANHÃO}

\begin{abstract}
Insects perform indispensable functions in the environments in which they occur, however, they are viewed negatively by man. Thus, knowing the perception/interaction of man with insects is extremely important to unite scientific and traditional knowledge. The present study aimed to analyze the perception and classification of insects by residents of the Vila Pindaré community, municipality of Buriticupu, Maranhão. The research took place from August to October 2019, using semi-structured questionnaires, carried out with 55 community residents. The data obtained revealed that the term "insect" was associated with several taxonomic groups, not belonging to the Insecta
\end{abstract}


class, such as spider (Araneae), followed by rat (Muridae) and scorpion (Scorpiones). In addition, most respondents have a negative feeling towards insects as disgusting, horrible, dangerous and disease-transmitting animals, however, they recognize their importance to nature.

KEYWORDS: Ethnoentomology; Popular knowledge; Ethnobiology.

\section{INTRODUÇÃO}

Os insetos são animais invertebrados, pertencentes à Classe Insecta, que abriga o maior grupo de animais em diversidade no planeta Terra, representando mais de $70 \%$ de todas as espécies de animais conhecidas (WIENS et al., 2015). Até o momento, já foram descritas cerca de um milhão de espécies no mundo e acredita-se que milhões ainda estão por serem descobertas (LEWINSOHN; PRADO, 2005). Eles são encontrados em quase todos os ecossistemas, mas somente um pequeno número de espécies adaptou-se à vida nos oceanos (GULLAN; CRANSTON, 2017).

Os insetos assumem importância socioeconômica muito grande devido à sua diversidade e abundância em ecossistemas naturais e antrópicos (CAJAIBA; SILVA, 2015). Além disso, os insetos praticam diversos processos ecológicos como: dispersão de sementes, ciclagem de matéria orgânica, polinização, dispersão de fungos, são fonte de alimento para outros animais, atuam no controle populacional de espécies de plantas através da herbivoria e de animais pela disseminação de doenças e parasitismo (CAJAIBA; SILVA, 2017a; CAJAIBA et al., 2020).

Os insetos não trazem somente benefícios ao homem. Segundo Sarwar e Sarwar (2018), os insetos interferem causando prejuízos a lavoura e a pecuária, com a predação e o parasitismo. Alguns são vetores de doenças como o mosquito Aedes aegypti que é a principal espécie responsável pela transmissão da dengue (BRADY; HAY, 2020).

A ciência que estuda a interação da população humana com os diversos recursos naturais dos ecossistemas que as incluem, buscando entender os conhecimentos e práticas culturalmente estabelecidas em consequência da estreita dependência homem - natureza, conferindo atenção especial aos processos de percepção, conhecimento e usos, é denominada Etnobiologia (POSEY, 1987).

A etnoentomologia estuda o conhecimento das populações acerca dos insetos e propõe soluções para desmistificação destes animais (COSTA NETO; PACHECO, 2004), tendo como foco o conhecimento, percepção e uso que as comunidades tradicionais ou locais (indígenas, quilombolas, campesinas e outras) possuem em relação aos insetos. Alencar et al. (2012) descreveram a etnoentomologia como a ciência que estuda o conhecimento entomológico do homem, avaliando sua interpretação, uso, crença, cultura, alimentação dentre vários outros fatores que estejam ligados entre os mesmos.

O conhecimento popular acerca dos insetos auxilia no fortalecimento da compreensão de como estes seres influenciam ou são influenciados pela vida humana. Dessa forma, os saberes da comunidade sobre o conhecimento da biodiversidade, compreendida a partir de suas vivências, estão amplamente ligados às formas de pensar, sentir e agir em relação aos elementos constituintes desta diversidade (COSTA NETO, 2002). Assim, possibilita ao ser humano perceber, classificar, identificar, categorizar e fazer uso dos insetos de acordo com as percepções e costumes particulares de cada cultura, estabelecendo desta forma uma gama de interações entre 
a população e as espécies animais na localidade onde vivem (POSEY, 1986; CAJAIBA; SILVA, 2017b).

A conservação dos insetos só é possível caso haja a aceitação pela comunidade; para isso, é necessário entender o modo de vida e de agir das pessoas e suas concepções sobre os insetos, de modo a conscientizar a comunidade humana sobre a importância desses organismos para o funcionamento dos serviços ecossistêmicos por eles prestados (ALVES et al., 2019).

Ainda há poucos estudos no campo da etnoentomologia realizados para o estado do Maranhão, nordeste do Brasil (ALVES et al., 2019). Desta forma, o presente trabalho teve por objetivo analisar a percepção e classificação de insetos pelos moradores da comunidade Vila Pindaré, município de Buriticupu, Maranhão, de forma a estabelecer uma comparação entre o conhecimento local e o científico, resgatando e valorizando os saberes da diversidade entomológica em diferentes aspectos, podendo contribuir para a elaboração de estudos futuros em diversas áreas.

\section{MATERIAL E MÉTODOS}

O estudo foi realizado na comunidade rural Vila Pindaré (Figura 1), pertencente ao município de Buriticupu, localizado entre às margens do Rio Pindaré e a Estrada de Ferro Carajás (EFC), no Estado do Maranhão, Nordeste do Brasil. A comunidade faz divisa com os municípios: Bom Jardim e Alto Alegre do Pindaré, distando aproximadamente $63 \mathrm{~km}$ da sede de Buriticupu.

FIGURA 1 - Localização da área de estudo: A) Brasil, B) Estado do Maranhão destacando o município de Buriticupu (em laranja), C) Sede municipal (Buriticupu, destacado pelo triângulo) e o povoado Vila Pindaré (destacado pelo círculo).

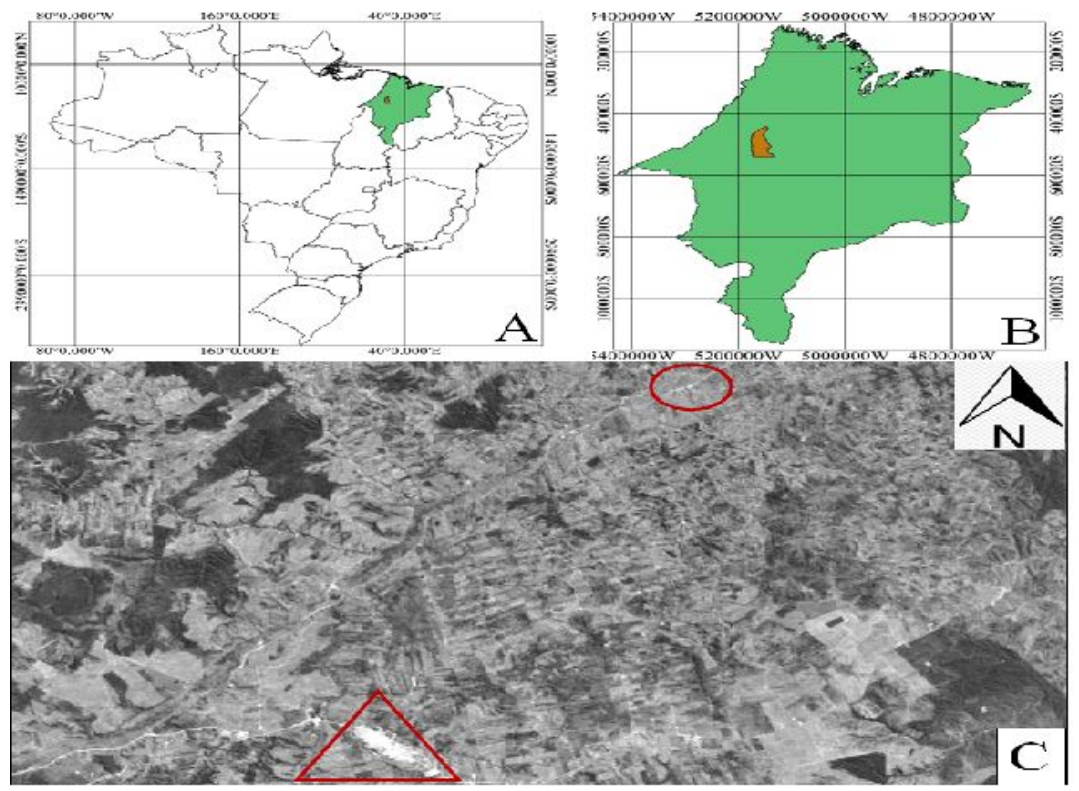

Fonte: Elaborada pelos autores (2020). 
Para a coleta de dados, foram realizadas entrevistas com a população no período de agosto a outubro de 2019 , com o objetivo de saber como os insetos são percebidos na comunidade e como estes são classificados com bases morfológica, comportamental e ecológica pelos moradores. A entrevista foi realizada com aplicação de formulário semiestruturado com base no método de geração de dados (POSEY, 1987).

Foram entrevistadas 55 pessoas com idade igual ou superior a 18 anos, priorizando o chefe familiar de cada residência. Foram utilizados métodos de pesquisa quantiqualitativa, tradicionalmente empregados em estudos etnobiológicos: entrevistas e apresentação de materiais visuais (BARDIN, 2016; MINAYO, 2017). Antes de qualquer entrevista, foi apresentado e entregue o Termo de Consentimento Livre e Esclarecido (TCLE) que era lido aos entrevistados a fim de explicar os objetivos deste trabalho. Cabe também destacar que, a todo momento, procurou-se adequar a linguagem do instrumento de pesquisa a cada entrevistado para facilitar o entendimento sobre as perguntas. Sendo assim, foi permitido ao entrevistado falar à vontade sobre os insetos para que os dados fossem coletados no decorrer de sua fala.

A análise dos dados foi realizada de forma quantiqualitativa, já que os resultados de algumas questões presentes no questionário puderam ser apresentados em forma de gráficos enquanto outras permitiram uma interpretação além da operacionalização das variáveis, pois buscavam a opinião dos moradores (BARDIN, 2016). É importante salientar que as porcentagens das respostas quando somadas não dão a quantidade total de entrevistas, tendo em vista que muitos entrevistados deram mais de uma resposta a determinadas perguntas, o que fez com que a somatória destas se diferencie da quantidade dos entrevistados. Para desenvolver as informações foram obtidas de forma individual, sendo que o entrevistado poderia expor suas experiências extrapolando as perguntas apresentadas (LIMA et al., 2018).

\section{RESULTADOS E DISCUSSÃO}

Participaram desta pesquisa 55 moradores da comunidade Vila Pindaré, sendo em sua maior parte do sexo feminino $(n=39 ; 71 \%)$. A idade média dos entrevistados foi de 38,79 anos (dp $\pm 12,07)$, destes, $65 \%(n=36)$ tinham idade entre 18 e 38 anos e $31 \%$ $(n=17)$ entre 39 e 59 anos. Em relação à escolaridade, a maioria dos participantes $(63,5 \%)$ possui o ensino médio completo, enquanto $29,5 \%$ possuem até o ensino fundamental e $7 \%$, ensino superior.

Os colaboradores quando questionados sobre "Para você, o que é um inseto?", $38 \%(n=21)$ definiram insetos de acordo com a seguinte tipologia de caracteres: conceitual, utilitário, ecológico, afetivo, nocivo, desprezível e estético. O caráter conceitual foi o mais citado "São animais invertebrados", respostas corretas, porém incompletas, pois não abrangem a totalidade de características destes animais (GULLAN; CRANSTON, 2017), pois, são normalmente agrupados nesta designação para vermes, insetos e outros artrópodes, os equinodermos (estrelas do mar, holotúrias ou pepinos-do-mar) e outras classes de animais sem esqueleto interno (BARNES et al., 2008).

Além disso, houve respostas que abordaram estas peculiaridades como "são animais asquerosos", "animais nocivos", "transmissores de doenças", "feio", "nojento", "pragas", "é algo perigoso", "animais que possuem venenos", "são pequenos animais", "animais que não possuem cérebro", "são animais que voa e não voa" e até "pertencem 
a grupos", insinuando propositalmente ou não, uma percepção sobre a sistemática e taxonomia.

Esses tipos de definições corroboram o que foi encontrado em diversos estudos etnozoológicos (TRINDADE et al., 2012; GUEDES et al., 2016), nos quais os participantes tendem a construir a etnocategoria "inseto" de acordo com a experiência vivenciada, uma vez que em alguns casos são negativa, ou até mesmo de acordo com o ambiente inserido e os meios de conhecimentos, ou pelas características encontradas em alguns insetos, como a aparência desagradável e a capacidade de atuar como vetores de doenças (CAJAIBA; SILVA, 2017b).

Os colaboradores foram indagados sobre o que pensavam ou sentiam ao ouvir a palavra insetos. As expressões pejorativas em relação aos insetos, $73 \%(n=40)$ dos entrevistados citaram respostas do ponto de vista negativo, os termos mais frequentes foram: medo, nojo/nojento, arrepio, perigo/perigoso, pavor, horror/horrível, alergia e receio (Tabela 1$)$. Em contrapartida, $27 \%(n=15)$ responderam que não pensa ou sente nada quando ouve a palavra insetos (Tabela 1).

Essa percepção negativa, como medo/ pavor/ repulsão, também foi encontrada em diversos estudos de cunho etnobiológicos, como os realizados por Trindade et al. (2012) e Guedes et al. (2016) com estudantes do ensino médio; Alves et al. (2019) com moradores do município de Buriticupu - MA; e também por Macedo e Soares (2012) no município de Paulo Afonso - BA.

TABELA 1 - Percentual de expressões pejorativas em relação aos insetos, segundo os entrevistados na comunidade Vila Pindaré.

\begin{tabular}{|c|c|c|}
\hline $\begin{array}{l}\text { Expressões } \\
\text { pejorativas }\end{array}$ & $\begin{array}{l}\text { Número } \\
\text { citações }\end{array}$ & Frequência (\%) \\
\hline Medo & 19 & $40 \%$ \\
\hline Nojo/nojento & 17 & $36 \%$ \\
\hline Arrepio & 3 & $6 \%$ \\
\hline Perigo/perigoso & 3 & $6 \%$ \\
\hline Pavor & 2 & $4 \%$ \\
\hline Horror/horrível & 2 & $4 \%$ \\
\hline Alergia & $\overline{1}$ & $2 \%$ \\
\hline Receio & 1 & $2 \%$ \\
\hline
\end{tabular}

A questão seguinte pretendia conhecer "qual importância dos insetos?". Os participantes atribuíram valores positivo e negativo. Desta forma, 20\% ( $n=11)$ dos informantes afirmaram que "os insetos não têm importância". Entretanto, a maior faixa das respostas foi de caráter positivo (Tabela 2$), 80 \%(n=44)$ informaram que os insetos têm alguma importância no meio ambiente, como: São fundamentais para o equilíbrio de nosso ecossistema e serve como alimento para diversos tipos de animais (E49, 30 anos); Na cadeia alimentar, na decomposição da matéria orgânica, na polinização das plantas que na sua maioria depende dos insetos para isso (E20, 29 anos); São importantes, porque são utilizados como alimentos para pássaros, peixes, répteis e anfíbios (E43, 23 anos).

Portanto, as respostas que categorizam os insetos positivamente associaram os insetos aos benefícios de suas funções (de importância econômica) como, por exemplo, a produção de mel, de remédios, entre outras (TRIPLEHORN; JOHNSON, 2015). 
Também mencionaram que esses animais são de extrema importância para a vida de outros animais e da natureza, remetendo ao conceito de relações ecológicas e teias alimentares. Resultados semelhantes podem ser encontrando em estudo realizado por Cajaiba e Silva (2014).

A percepção da importância dos insetos foi relatada entre os indivíduos em que a maioria já possuía o ensino médio e alguns com formação superior, podendo-se perceber a influência do meio acadêmico na percepção de componentes do cotidiano desses informantes. Esse resultado é semelhante ao encontrado por Costa Neto e Pacheco (2004, p. 84), e por Cajaiba (2014), os quais afirmam que o ensino formal influencia "a maneira como os organismos são percebidos e classificados".

TABELA 2 - Percentual da percepção dos entrevistados sobre a importância dos insetos, na comunidade Vila Pindaré.

\begin{tabular}{lcc}
\hline Importância dos insetos & $\begin{array}{c}\text { Número de } \\
\text { citações }\end{array}$ & Frequência (\%) \\
\hline Na adubação da terra & 1 & $2 \%$ \\
Produção de remédios & 1 & $2 \%$ \\
Produção de mel & 3 & $5 \%$ \\
É fundamental para o & 7 & $13 \%$ \\
ecossistema & & \\
São decompositores & 7 & $13 \%$ \\
Na cadeia alimentar & 11 & $20 \%$ \\
Polinização das plantas & 14 & $25 \%$ \\
Não tem importância & 11 & $20 \%$ \\
\hline
\end{tabular}

Quando questionados sobre os malefícios dos insetos, a maioria dos colaboradores $(68,5 \%)$ respondeu que os insetos são transmissores de doenças, e, entre estas, as mais citadas foram: dengue, Chikungunya, febre amarela, alergia, Zika, malária, doenças de chagas e hepatite A. Houve ainda, outras definições como: "Destroem as plantações" e "Causam danos à agricultura". Animais como mosquito da dengue, barbeiro e baratas apareceram com maior número de citações, sendo "insetos" causadores de malefícios. O mosquito da dengue (Aedes aegypti) também foi uns dos mais citados em estudo realizado por Alves et al. (2019) com moradores de Buriticupu, Maranhão.

Em estudo conduzido por Costa-Neto e Pacheco (2004), outros insetos foram citados como transmissores de doença ou inseto praga: barbeiro $(8,4 \%)$, barata $(6,6 \%)$, mosca $(2,8 \%)$, muriçoca $(2,8 \%)$ e gafanhoto $(2,8 \%)$. Ainda, animais pertencentes a outros táxons foram citados como inseto praga ou transmissores de doença, a saber: aranha $(5,6 \%)$, rato $(4,7 \%)$, carrapato $(3,7 \%)$ e escorpião $(3,7 \%)$. Resultados semelhantes também apareceu em estudos realizados por Alves et al. (2019) como sendo um "inseto" causador de doenças.

Com relação ao conhecimento dos entrevistados sobre como os insetos nascem (origem), 69\% responderam corretamente, destes, 45,5\% responderam que "se originam de ovos" e $23,5 \%$ informaram que "os insetos nascem de larvas". Apenas $22 \%$ relataram não saber; outros $9 \%$ acreditam que os insetos surgem "de água parada" ou "eles nascem da sujeira". Resultados diferentes foram encontrados por Cajaiba e Silva (2014) ao analisar as percepções dos alunos do ensino fundamental no município de 
Uruará, Pará, onde a maioria dos discentes não souberam responder corretamente sobre a forma de reprodução dos insetos e por Alves et al. (2019) ao analisarem o conhecimento etnoentomológico dos moradores do município de Buriticupu, Maranhão, onde a maioria dos entrevistados não soube informar como nascem os insetos.

Com relação ao conhecimento dos entrevistados sobre como os insetos vivem, $40 \%$ responderam que os insetos vivem "na terra e em florestas", $29 \%$ citaram que os insetos vivem "nas regiões frias", $22 \%$ informaram que "os insetos vivem em qualquer lugar" e 9\% apontaram o "esgoto" como lugar onde vivem os insetos. Desta forma, em uma escala temporal, os insetos vivem na Terra há cerca de 350 milhões de anos, muito mais antigos quando comparados a espécie humana. A quantidade de espécies de insetos supera a de todos os outros grupos de animais terrestres e evoluíram adaptando-se a quase todos os tipos de habitat existentes (TRIPLEHORN; JOHNSON, 2015).

Com relação aos saberes etnoentomológico, os participantes mencionaram ao todo 41 tipos de animais; destes, 25 são classificados sistematicamente na classe Insecta (Tabela 3) e 16 são classificados em 10 táxons diferentes, entre os quais se destacaram a aranha (Araneae), seguido por rato (Muridae) e escorpião (Scorpiones) (Tabela 4).

TABELA 3 - Animais citados pelos participantes do povoado Vila Pindaré, e classificados na classe Insecta.

\begin{tabular}{|c|c|c|c|c|}
\hline Ordem & Nome vulgar & Família/Espécie & $\begin{array}{c}\text { Número de } \\
\text { citações }\end{array}$ & $\begin{array}{c}\text { Frequência } \\
(\%)\end{array}$ \\
\hline \multirow{2}{*}{ Blattodea } & Barata & Blattidae & 48 & $13,5 \%$ \\
\hline & Cupim & - & 6 & $1,7 \%$ \\
\hline \multirow{4}{*}{ Coleoptera } & Besouro/Cascudo & - & 24 & $6,7 \%$ \\
\hline & Rola-bosta & Scarabaeidae & 1 & $0,3 \%$ \\
\hline & Joaninha & Coccinellidae & 3 & $0,8 \%$ \\
\hline & Vagalume & Lampyridae & 1 & $0,3 \%$ \\
\hline \multirow[t]{4}{*}{ Diptera } & Mosquito-da-dengue & Culicidae/Aedes aegypti & 46 & $12,9 \%$ \\
\hline & Mosquito & Simuliidae & 32 & $9 \%$ \\
\hline & Muriçoca/Pernilongo & Culicidae & 13 & $3,6 \%$ \\
\hline & Mosca & $\begin{array}{l}\text { Muscidae/Musca } \\
\text { domestica }\end{array}$ & 25 & $7 \%$ \\
\hline \multirow{4}{*}{ Hemiptera } & Barbeiro & Reduviidae & 9 & $2,5 \%$ \\
\hline & Cigarra & - & 4 & $1,2 \%$ \\
\hline & Percevejo & - & 2 & $0,5 \%$ \\
\hline & Pulgão & Aphididae & 1 & $0,3 \%$ \\
\hline \multirow[t]{4}{*}{ Hymenoptera } & Formiga & Formicidae & 31 & $8,7 \%$ \\
\hline & Abelha & Apoidea & 28 & $7,8 \%$ \\
\hline & Marimbondo & Vespidae & 5 & $1,4 \%$ \\
\hline & Vespa & - & 3 & $0,8 \%$ \\
\hline \multirow[t]{3}{*}{ Lepidoptera } & Lagarta & - & 11 & $3 \%$ \\
\hline & Borboleta & - & 25 & $7 \%$ \\
\hline & Mariposa & - & 4 & $1,2 \%$ \\
\hline \multirow{3}{*}{ Orthoptera } & Grilo & Gryllidae & 13 & $3,6 \%$ \\
\hline & Gafanhoto & Acrididae & 15 & $4,2 \%$ \\
\hline & Esperança & Tettigoniidae & 2 & $0,5 \%$ \\
\hline Phthiraptera & Piolho & Pediculidae & 5 & $1,5 \%$ \\
\hline
\end{tabular}


TABELA 4 - Animais citados pelos participantes do povoado Vila Pindaré e classificados em outros táxons, não pertencentes à classe Insecta.

\begin{tabular}{|c|c|c|c|c|}
\hline Classe & Nome vulgar & Ordem/ Família & $\begin{array}{l}\text { Número } \\
\text { de } \\
\text { citações }\end{array}$ & $\begin{array}{c}\text { Frequênci } \\
\text { a (\%) }\end{array}$ \\
\hline \multirow[t]{2}{*}{ Amphibia } & Sapo & Anura & 1 & $1,3 \%$ \\
\hline & Aranha/ & Araneae & 24 & $30,8 \%$ \\
\hline \multirow[t]{2}{*}{ Arachnida } & Caranguejeira & Ixodida & 6 & $7,7 \%$ \\
\hline & $\begin{array}{l}\text { Carrapato } \\
\text { Escorpião }\end{array}$ & Scorpiones & 8 & $10,2 \%$ \\
\hline Chilopoda & $\begin{array}{l}\text { Piolho-de- } \\
\text { Cobra/Lacraia }\end{array}$ & $\begin{array}{l}\text { Scolopendromorph } \\
\text { a }\end{array}$ & 4 & $5,1 \%$ \\
\hline Diplopoda & Gangugir/Embuá & Julidae & 3 & $3,8 \%$ \\
\hline \multirow[t]{2}{*}{ Gastropoda } & Caramujo & Pulmonata & 1 & $1,3 \%$ \\
\hline & Lesma & Stylommatophora & 3 & $3,8 \%$ \\
\hline \multirow[t]{2}{*}{ Mammalia } & Rato & Muridae & 12 & $15,4 \%$ \\
\hline & Morcego & Chiroptera & 2 & $2,6 \%$ \\
\hline Malacostraca & Caranguejo & Brachyura & 2 & $2,6 \%$ \\
\hline \multirow[t]{2}{*}{ Oligoqueta } & Minhoca & Haplotaxida & 3 & $3,8 \%$ \\
\hline & Cobra & Serpentes & 2 & $2,6 \%$ \\
\hline \multirow[t]{2}{*}{ Reptilia } & Lagartixa/Labigó & Gekkonidae & 3 & $3,8 \%$ \\
\hline & Lagarto & Squamata & 2 & $2,6 \%$ \\
\hline $\begin{array}{l}\text { Scolopendromorp } \\
\text { ha }\end{array}$ & Lacraia & Scolopendridae & 2 & $2,6 \%$ \\
\hline
\end{tabular}

Categorizar como insetos, outros animais pertencentes a diversos grupos taxonômicos é algo corriqueiro, sendo observado em diversas comunidades. Estudos etnozoológicos atestam que, as comunidades classificam na mesma categoria dos insetos, um elevado número de espécies de outros táxons, como os observados por Alves et al. (2019), Cajaiba e Silva (2014). Portanto, os "insetos" como uma etnocategoria taxonômica parece ocorrer como um padrão nos sistemas de classificação etnobiológicos (COSTA NETO; CARVALHO, 2000; COSTA NETO; PACHECO, 2004).

Este padrão pode ser explicado pela recente hipótese da ambivalência entomoprojetiva, segundo a qual os seres humanos tendem a projetar sentimentos de nocividade, periculosidade, irritabilidade, repugnância e menosprezo aos animais associados à categoria "inseto" determinada culturalmente (ALENCAR et al., 2012).

Os resultados estão de acordo com outros estudos etnobiológicos, onde observa-se que as populações classificam, com os insetos, um elevado número de espécies classificados em diversos grupos taxonômicos (JORGE et al., 2014). De acordo com Silva e Ramos (2019), a categoria etnozoológica "inseto" construída no cotidiano das comunidades são influenciadas pela cultura local. Dessa forma, os artrópodes em geral, assim como outros animais, são classificados como insetos (ALVES et al., 2019).

Os insetos com maior número de citações são aqueles que mais fazem parte do cotidiano das pessoas, provavelmente espécies que se relacionam melhor com a presença da espécie humana. Entretanto, alguns dos entrevistados categorizaram 
como insetos, aranha, rato, escorpião, carrapato entre outros respectivamente. Tais associações possuem um forte viés cultural, uma vez que o termo "inseto" acaba sendo usado como sinônimo de "feio", "maléfico", "ruim", entre outros (TRINDADE et al., 2012).

\section{CONCLUSÕES}

Os resultados revelaram aspectos socioculturais, econômicos e biológicos intimamente relacionados à visão que os moradores da comunidade Vila Pindaré, município de Buriticupu conhecem sobre os insetos, e que muitas das representações construídas pelos moradores são fortemente influenciadas pelo conhecimento adquirido por meio das interações e práticas sociais cotidianas.

Diante dos resultados obtidos, pode-se afirmar que os moradores categorizam dentro da Classe Insecta outros animais pertencentes a diferentes táxons. Esse tipo de classificação, conceituação e conhecimento dos entrevistados sobre esses artrópodes estão relacionados aos sentimentos negativos, repúdio e até mesmo medo e nojo, apesar de alguns ainda reconhecerem os benefícios que estes podem trazer para o ambiente.

O fato de uma expressiva parcela de entrevistados terem reportado a importância dos insetos no meio ambiente faz supor que, apesar de ainda serem vistos com repugnância e sem utilidade para algumas pessoas, os participantes demonstraram sensibilidade quanto aos benefícios que estes seres propiciam, o que pode, consecutivamente, atuar na manutenção da entomofauna local.

Portanto, os trabalhos relacionados ao conhecimento acerca dos insetos tornamse importantes para compreender a forma como os diferentes povos percebem os insetos. Além disso, o conhecimento sobre os insetos pode auxiliar na compreensão do papel deste grupo no ambiente, assim como mudar as relações humanas com eles. Desta maneira, é necessária a divulgação desses trabalhos, além do trabalho de assuntos relacionados ao tema no ensino formal e informal de forma a buscar uma mudança na visão negativa relacionada aos insetos.

\section{REFERÊNCIAS}

ALENCAR, J.B.R.; SILVA, E.F.; SANTOS, V.M.; SOARES, H.K.L.; LUCENA, R.F.P.; BRITO, C.H. Percepção e uso de "insetos" em duas comunidades rurais no semiárido do estado da Paraíba. Revista de Biologia e Farmácia, v. 9, p. 72-91, 2012.

ALVES, A.C.; BEIMS, A.A.; ALENCAR, E.M.; LIMA, F.A.; SILVA, K.M.A.; SOUSA, E.S.; CAJAIBA, R.L. Conhecimento etnoentomológico dos moradores do município de Buriticupu, Maranhão, Brasil. Biotemas, v. 32, p. 97-105, 2019.

BARDIN, L. Análise de conteúdo. Trad. Luís Antero Reto, Augusto Pinheiro. 3aㅡ reimp. da 1ㄹed. Lisboa: Edições 70, 2016.

BARNES, P.; CALOW, P.; OLIVE, P.J.W.; GOLDING, D.W.; SPICER, J.I. Os Invertebrados: Uma Síntese. 2. ed. São Paulo: Atheneu Editora, 2008. 
BRADY, O.; HAY, S. The global expansion of dengue: How Aedes aegypti mosquitoes enabled the first pandemic arbovirus. Annual Review of Entomology, v. 65, p. 191-208, 2020.

CAJAIBA, R.L. Difficulty of science and biology teachers to teach entomology in elementary and high schools in the state of Pará, Northern Brazil. American Journal of Educational Research, v. 2, p. 389-392, 2014.

CAJAIBA, R.L.; PÉRICO, E.; SILVA, W.B.; CARON, E.; BUSS, B.C.; DALZOCHIO, M.S.; SANTOS, M. Are primary forests irreplaceable for sustaining Neotropical landscapes biodiversity and functioning? Contributions for restoration using ecological indicators. Land Degradation \& Development, v. 31, p. 508-517, 2020.

CAJAIBA, R.L.; SILVA, W.B. Abundância e diversidade de coleópteros de solo em fragmentos de capoeira ao entorno da zona urbana do município de Uruará-PA, Brasil. EntomoBrasilis, v. 8, p. 30-37, 2015.

CAJAIBA, R.L.; SILVA, W.B. Aulas práticas de Entomologia como mecanismo facilitador no aprendizado de taxonomia para alunos do ensino médio. Scientia Amazonia, v. 6 , p. 107-116, 2017b.

CAJAIBA, R.L.; SILVA, W.B. Diversidade e sazonalidade de Cydnidae (Insecta: Hemiptera: Heteroptera) em diferentes ecossistemas no estado do Pará, norte do Brasil. Revista Brasileira de Biociências, v. 15, p. 32-37, 2017 a.

CAJAIBA, R.L.; SILVA, W.B. Percepção dos alunos do ensino fundamental sobre os insetos antes e após aulas práticas: Um estudo de caso no município de Uruará-Pará, Brasil. Enciclopédia Biosfera, v. 10, p. 2510-2521, 2014.

COSTA NETO, E.M. A utilização ritual de insetos em diferentes contextos socioculturais. Sitientibus, v. 2, p. 97-103, 2002.

COSTA NETO, E.M.; CARVALHO, P.D. Percepção dos insetos pelos graduandos da Universidade Estadual de Feira de Santana, Bahia, Brasil. Acta Scientiarum v. 22, p. 423-428, 2000.

COSTA NETO, E.M.; PACHECO, J.A. A construção do domínio etnozoológico "inseto" pelos moradores do povoado de Pedra Branca, Santa Terezinha, Estado da Bahia. Acta Scientiarum, v. 26, p. 81-90, 2004.

GUEDES, R.S.; SANTOS, W.S.; MEDEIROS, F.S.; ALMEIDA, A.B. Percepção entomológica de alunos do ensino médio em escolas da cidade de Patos, Paraíba, Brasil. Revista Verde de Agroecologia e Desenvolvimento Sustentável, v. 11, p. 01-07, 2016

GULLAN, P.J.; CRANSTON, P.S. Insetos: Fundamentos da Entomologia. 5. ed. São Paulo: Roca, p. 460, 2017. 
Jorge, V.; Sánchez, D.; Souza, M.; Pasa, M.; Rezende, E. Conhecimentos entomológicos pelos moradores do bairro Verdão em Cuiabá - MT. Enciclopédia Biosfera, v. 10, p. 3814-3824, 2014.

LEWINSOHN, T.M.; PRADO, P.I. Quantas espécies há no Brasil? Megadiversidade, v. 1, p. 36-42, 2005.

LIMA, E.R.R.; SOUSA, E.S.; MARTINS, J. C.; CAJAIBA, R.L. Conhecimentos e atitudes dos moradores de um município da Amazônia legal maranhense em relação aos morcegos. Enciclopédia Biosfera, v. 15, p. 1001-1014, 2018.

MACEDO, E.V.; SOARES, I.M.F. Percepção de Insetos por moradores de zonas urbanas do município de Paulo Afonso, Bahia, Brasil. Revista Ouricuri, v. 2, p. 11-122, 2012.

MINAYO, M.C. Amostragem e saturação em pesquisa qualitativa: consensos e controvérsias. Revista Pesquisa Qualitativa, v. 5, p. 1-12, 2017.

POSEY, D.A. Ethnoentomological survey of Brazilian Indians. Entomology General, v. 12, p. 191-202, 1987.

POSEY, D.A. Introdução: Etnobiologia, teoria e prática. In: Ribeiro, D. Suma Etnológica Brasileira, v. 1, p. 15-25, 1986.

Sarwar, S.; Sarwar, M. Involvement of insects (Insecta: Artropoda) in spreading of plant pathogens and approaches for pests management. American Journal of Microbiology and Immunology, v. 3, p. 1-8, 2018.

SILVA, J.A.; RAMOS, M.A. Conhecimentos tradicionais e o ensino de ciências na educação escolar quilombola: um estudo etnobiológico. Investigações em Ensino de Ciências, v. 24, p. 121-146, 2019

TRINDADE, O.S.N.; SILVA JÚNIOR, J.C.; TEIXEIRA, P.M.M. Um estudo das representações sociais de estudantes do ensino médio sobre os insetos. Revista Ensaio Pesquisa em Educação em Ciências, v. 10, p. 37-50, 2012.

TRIPLEHORN, C.A.; JOHNSON, E N.F. Estudo dos insetos. 2. ed. São Paulo: Cengage Learning, p. 809, 2015.

WIENS, J.J.; LAPOINT, R.T.; WHITEMAN, N.K. Herbivory increases diversification across insect clades. Nature Communications, v. 6, p. 73-80, 2015. 